\title{
Evaluation of the mutagenic potential of propoxur and methyl parathion using polytene chromosomes of Anopheles stephensi
}

\author{
A sha Chaudhry, Preety Bhinder*, Ram K umar and R avneet K aur \\ Department of Zoology, Panjab University, Chandigarh-160014, INDIA \\ *Corresponding author. E-mail: preety.bhinder@yahoo.com
}

\begin{abstract}
The mutagenicity of two pesticides, propoxur and methyl parathion was evaluated by using polytene chromosomes of Anopheles stephensi. The results were based on the frequency of various structural aberrations encountered in the polytene chromosomes of the larvae treated with $\mathrm{LC}_{20}$ of propoxur and methyl parathion separately. Propoxur induced a total of 67 aberrations as against 15 in the controls while methyl parathion induced 53 aberrations as against 13 in the controls. These aberrations were dominated by inversions, translocations, deletions, ectopic pairing, asynapses, breaks, fusions and induced puffing. The frequency of propoxur induced aberrations was highest in chromosome 3R followed by 2R, 3L, 2L and X-chromosome. Methyl parathion induced highest number of aberrations in $2 \mathrm{R}$ followed by $2 \mathrm{~L}, 3 \mathrm{R}, 3 \mathrm{~L}$ and $\mathrm{X}$-chromosomes. This study suggests that larval polytene chromosomes are sensitive indicators of pesticide genotoxicity in which both propoxur and methyl parathion are significantly chromotoxic for the genome of a mosquito taken as an experimental insect.
\end{abstract}

Keywords: Anopheles stephensi, Methyl parathion, Mutagenicity, Polytene chromosomes, Propoxur

\section{INTRODUCTION}

With the increase in population pressure, the task of increasing food productivity has become a global priority. Major hindrance in accomplishing this goal is the loss of productivity due to pests for which the use of pesticides had been indispensable. However, widespread use of pesticides in agriculture has created serious problems of environmental pollution and health hazards for man and his livestock as many of the chemical formulations have been identified as potential sources of damage to the genetic material. This has greatly increased the need for risk assessment of harmful agents by employing a variety of experimental procedures (Sharma et al 1985; Zaman et al., 1994; Chaudhry and Anand, 2004, 2005; Chaudhry and Barna, 2006; Chaudhry and Bhinder, 2009; Bansal and Chaudhry, 2011). The analysis of induced chromosomal aberrations is a much favoured parameter of study for the objective assessment of genotoxicity of pesticides, drugs and radiations (Rabbani and Kitzmiller, 1974; Jain and Sarbhoy, 1988; Agrawal, 1999). While using invertebrates as experimental test systems, the mosquitoes have an added advantage in having giant sized polytene chromosomes, very small diploid number of chromosomes $(2 n=6)$ and a short life span, therefore, they have been preferred for studying the induced structural changes in their polytene chromosomes (Rubinstenin and Clever, 1972; Garcia and Sanchez, 1988; Chaudhry et al., 2005). As for the use of larval salivary polytene chromosomes of Anopheles mosquito as an experimental model, Sharma and his co-workers have some of the valuable contributions in evaluating the harmful effects of a number of environmental mutagens and drugs (Sharma et al., 1985, 1988, 1989a, b, 1990). In this context, the present paper deals with the mutagenicity evaluation of two pesticides, propoxur and methyl parathion which belong to the class of carbamates and organophosphates respectively. Both the pesticides have broad spectrum insecticidal activity against a number of arthropod pests. In the present investigations, the mutagenic potential of sublethal concentration of these pesticides was evaluated on the basis of chromosomal aberrations in the larval salivary polytene chromosomes of Anopheles stephensi.

\section{MATERIALS AND METHODS}

An. stephensi, an experimental insect for the present investigation was collected from its resting sites inside human dwellings and the cattle sheds in the rural area around Chandigarh. The gravid females were kept in breeding cages where they were allowed to oviposit in water filled petridishes. The rearing of these eggs from first to fourth instar was carried out under suitable conditions of temperature and humidity in the mosquito rearing laboratory while experimental stocks were maintained in the BOD incubator. Larval stages were fed on a protein rich diet of finely powdered dog biscuits and yeast tablets mixed in the ratio of 6:4 (Singh et al., 1975; Clements, 1996). Propoxur is a non-systemic insecticide which belongs to the category of widely used 
carbamate pesticides. It has a molecular formula $\mathrm{C}_{11} \mathrm{H}_{15} \mathrm{NO}_{3}$ molecular weight 416.3 and $\mathrm{CAS}$ number 11426-1. Methyl parathion is also a non-systemic insecticide belonging to the category of organophosphates which is used for the control of chewing and sucking insects. It has a molecular formula $\mathrm{C}_{8} \mathrm{H}_{10} \mathrm{NO}_{5} \mathrm{PS}$, molecular weight 263.2 and CAS number 298-00-0. The $\mathrm{LC}_{20}$ of both the pesticides was calculated by probit analysis (Finney, 1971). Accordingly, the concentration values as per the probit of kill were $1.9 \times 10^{-2} \mu \mathrm{l} / \mathrm{ml}$ and $1.6 \times 10^{-2} \mu \mathrm{l} / \mathrm{ml}$ respectively. Second instar larvae were treated for $24 \mathrm{~h}$ in pesticide containing water after which they were transferred to pesticide free water and allowed to grow upto early fourth instar stages for chromosome preparations. The temporary squash preparations of the polytene chromosomes of healthy fourth instar larvae of treated and control stocks were made by staining the salivary glands in $2 \%$ lacto-aceto-orcein stain (French et al., 1962). The effect of both the pesticides was measured in terms of the percentage frequency of various types of structural aberrations like inversion, deletion, fusion, asynapses and translocation in the right and left arm of each chromosome of An. stephensi. The data of various chromosomal aberrations was then statistically analyzed by employing the Student's t-test.

\section{RESULTS AND DISCUSSION}

An. stephensi carries a metaphase karyotype of six unequal homologous pairs comprised of a smallest pair of acrocentric sex chromosomes (XX-Female, XY- Male) and two pairs of autosomes out of which the larger pair consists of submetacentric homologues while the smaller consists of metacentric homologues. In the salivary gland cells this diploid number is represented by three highly polytenized chromosomes, due to the somatic pairing of homologues. As for the mutational effect on these chromosomes propoxur induced a total of 67 aberrations as against 15 in the controls while methyl parathion induced 53 aberrations as against 13 in the controls. In propoxur treated larvae, there were 20 heterozygous paracentric inversions, 2 deletions, 24 ectopically paired heterochromatic bands, 7 asynaptic regions of intimately paired homologues, 2 translocations, 2 cases of induced puffing, 8 chromosomal fusions and 2 chromosomal breaks. Similarly, in methyl parathion treated larvae, there were 43 inversions, 4 deletions, 1 asynaptic region and 5 translocations. Based on the involvement of different chromosomes, the right arm of chromosome 3 (3R) was found to be the most susceptible to propoxur while the right arm of chromosome 2 (2R) was most susceptible to methyl parathion, as the incidence of mutations was highest in these two chromosomal elements. Accordingly, the frequency of various aberrations induced with propoxur in individual chromosomal arm was: $2 \mathrm{~L}-3.00 \pm$ 
(a)

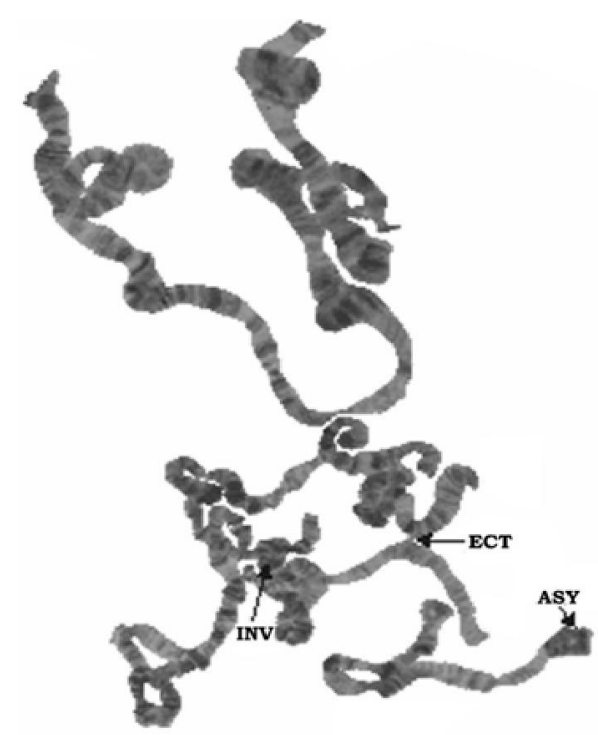

(c)

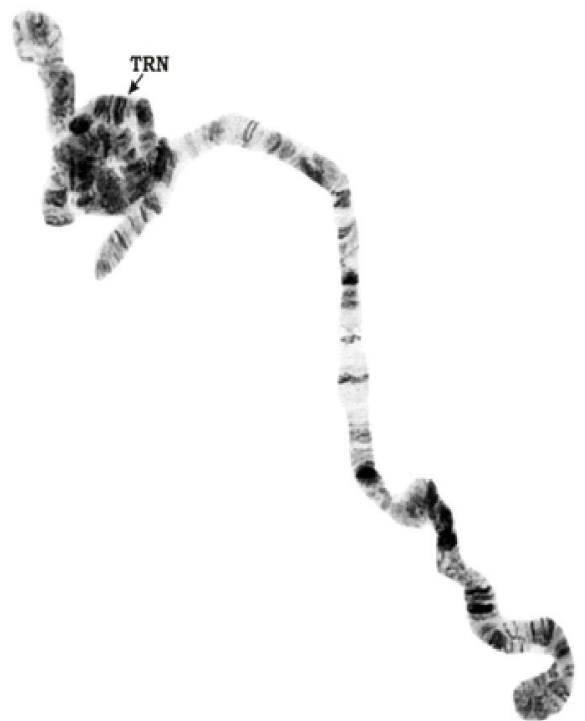

(b)

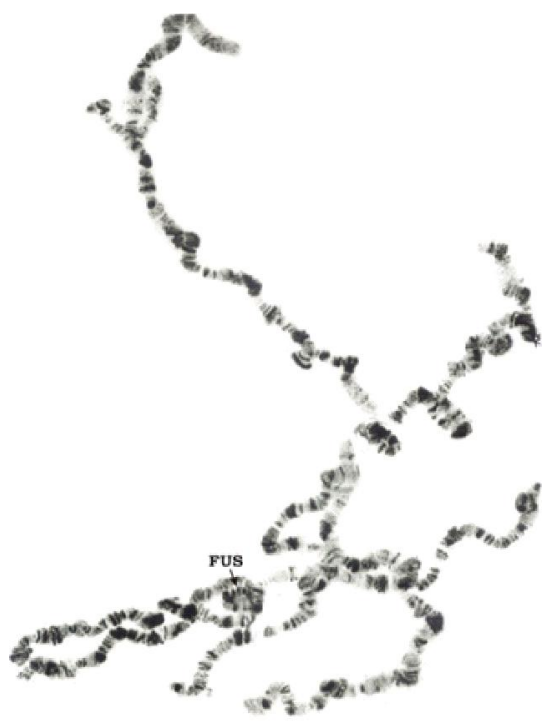

(d)

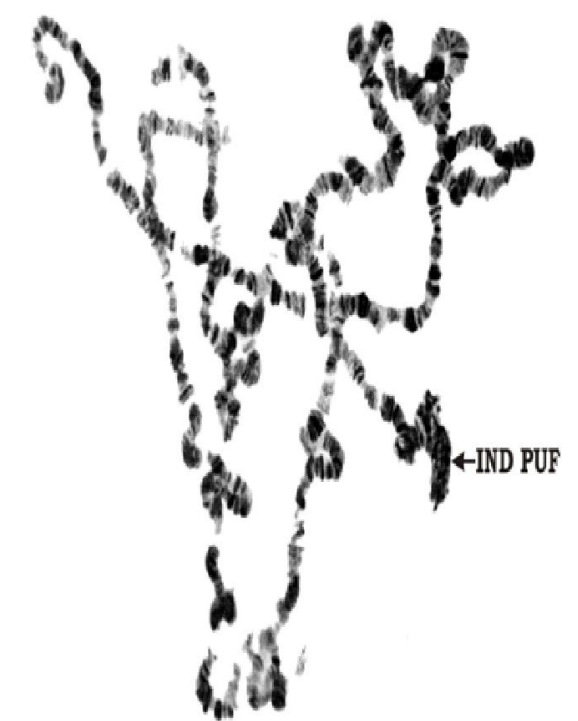

Fig. 2. Aberrations in the polytene chromosomes of An. stephensi treated with propoxur (a) Interchromosomal ectopic pairing (ECT) between chromosomal arms 3R and 3L; $3 \mathrm{~L}$ with inversion (INV); X-chromosome with terminal asynapsis (ASY). (b) Chromosomal fussion (FUS).(C) Ttranslocation (TRN) between chromosomal arms $2 \mathrm{~L}$ and $3 \mathrm{~L}$. (d) Induced puffing (IND PUF) in chromosomal arm 3R.

$1.16,2 \mathrm{R}-6.00 \pm 1.16,3 \mathrm{~L}-4.67 \pm 1.06,3 \mathrm{R}-7.00 \pm 0.58, \mathrm{X}-$ $1.67 \pm 0.33$. With this, the susceptibility of different chromosomal arms for the insecticide propoxur was found in order: $3 R>2 R>3 L>2 L>X$ (Fig. 1, Tables 1, 3). In the same way, the frequency of methyl parathion induced aberrations was: $2 \mathrm{~L}-1.6 \pm 0.70,2 \mathrm{R}-3.6 \pm 0.60,3 \mathrm{~L}-$ $1.2 \pm 0.50,3 \mathrm{R}-1.6 \pm 0.70, \mathrm{X}-0.2 \pm 0.0$. Hence the susceptibility of different chromosomal arms for methyl parathion was found in order: $2 \mathrm{R}>2 \mathrm{~L}=3 \mathrm{R}>3 \mathrm{~L}>\mathrm{X}$ (Fig. 2, Tables 2, 3). From the data a significant increase in the incidence of mutations was clearly evident in which the most frequent type were heterozygous paracentric inversions forming characterstic "inversion loops". Since, inversion is two break mutations, it suggests the elevated incidence of interstitial chromosome breaks. An ectopic pairing takes place due to sequence homologies in the DNA rich bands located at different loci in the same or in different chromosomes which results in the deeply stained heterochromatic thread like connections between them (Barr and Ellison, 1972). In case of asynapses of the somatically paired polytenic homologues, it is attributed to the degradation of the binding proteins which maintain

Table 2. Analysis of chromosomal aberrations in control and methyl parathion treated stocks of An. stephensi larvae.

\begin{tabular}{lccccc}
\hline Types of stock & Inversions & Deletions & Asynapses & Translocation & ' $\mathrm{t}$ ' value \\
\hline Control & $3.4 \pm 0.5$ & 0.00 & $0.2 \pm 0.00$ & 0.00 & \multirow{2}{*}{$3.5^{*}$} \\
Treated & $8.6 \pm 1.2$ & $0.8 \pm 0.40$ & $0.2 \pm 0.00$ & $1.0 \pm 0.40$ & \\
\hline
\end{tabular}


(a)

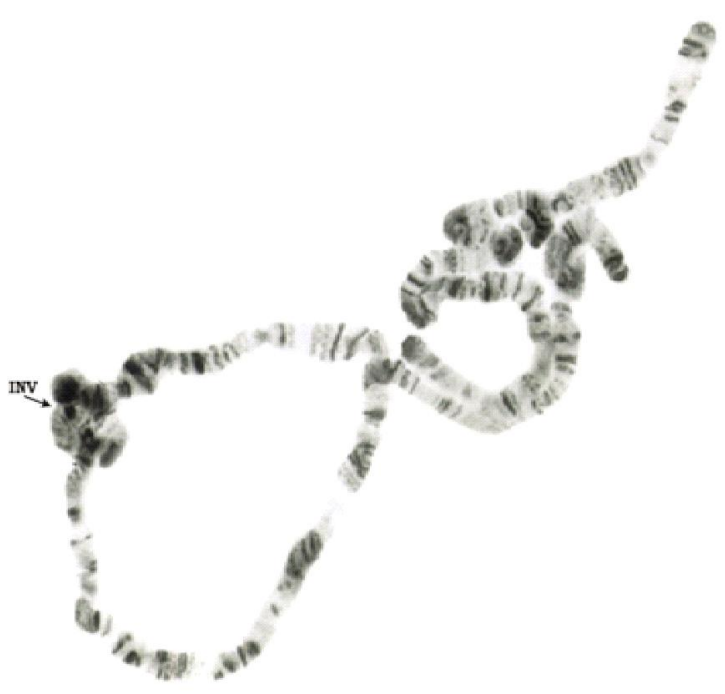

(c)

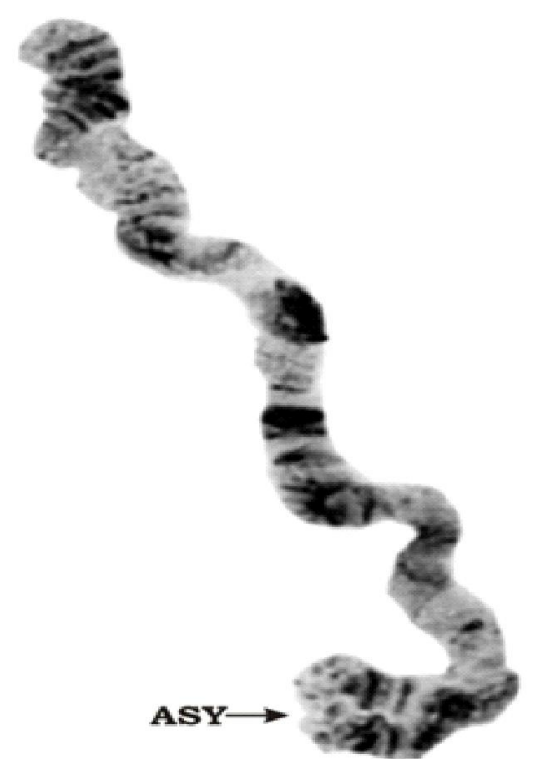

(b)

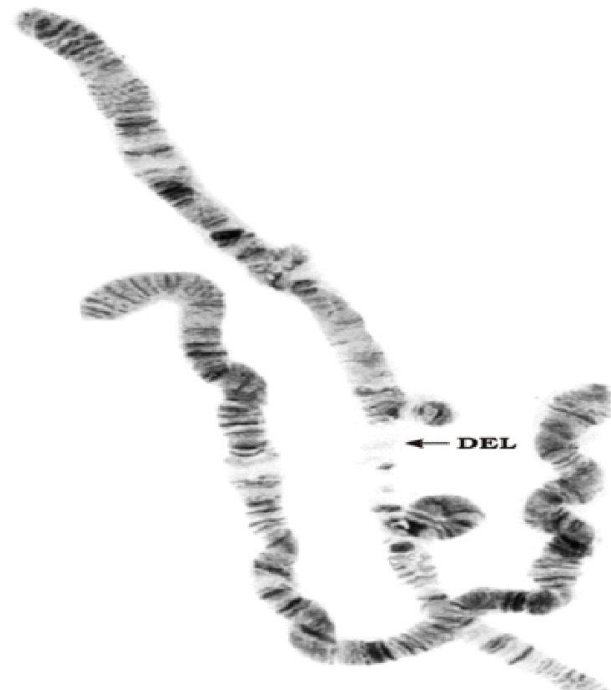

(d)

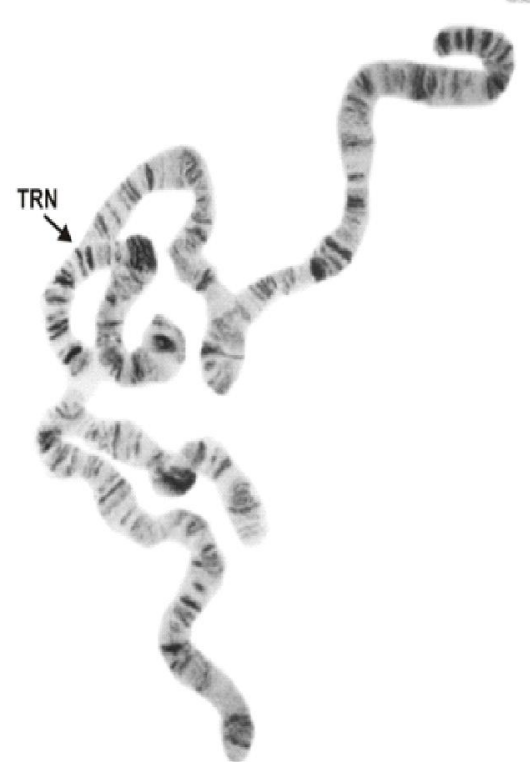

Fig. 2. Aberrations in the polytene chromosomes of An. stephensi treated with methyl parathion (a) Inversion (INV) in chromosomal arm 2R. (b) D eletion (DEL) in chromosomal arm 2L. (c) X-chromosome with terminal asynapsis (ASY). (d) Translocation (TRN) of unidentified chromosome into $2 R$.

the multistranded nature of polytene chromosomes (Evans, 1977; Jain and Sarbhoy, 1988). In addition to chromosomal mutations, some of the earlier studies also show that propoxur significantly increased the chromosomal aberrations in the bone marrow cells of mice (Agrawal, 1999; Siroki et al., 2001). In a similar set of investigations Lin et al. (2007) also reported the induction of different types of chromosomal aberrations which also included sister chromatid exchanges in the Chinese hamster ovarian cells. As for the genotoxic status of methyl parathion several workers have tried to evaluate its harmful effects on the genetic material of a variety of test organisms. For example, increased frequency of chromosomal aberrations, sister chromatid exchanges and the production of micronuclei was observed in mice, rat, Drosophila and human cell in culture (De Cassia et al., 1982, Grover and Malhi, 1985; Mathew et al., 1990; Rupa et al., 1989, 1990, 1991; Kumar etal., 1993; Vijayaraghavan

Table 3. Analysis of aberrations in individual chromosomal arm in propoxur and methyl parathion treated stocks of An. stephensi larvae.

\begin{tabular}{llccccc}
\hline Pesticide & Types of stock & $\mathrm{X}$ & $2 \mathrm{R}$ & $2 \mathrm{~L}$ & $3 \mathrm{R}$ & $3 \mathrm{~L}$ \\
\hline Propoxur & Control & $0.33 \pm 0.27$ & $2.00 \pm 0.58$ & $0.33 \pm 0.27$ & $1.00 \pm 0.41$ & $1.33 \pm 0.33$ \\
& Treated & $1.67 \pm 0.33$ & $6.00 \pm 1.16$ & $3.00 \pm 1.16$ & $7.00 \pm 0.58$ & $4.67 \pm 1.06$ \\
Methyl parathion & Control & $0.2 \pm 0.0$ & $0.8 \pm 0.40$ & $0.4 \pm 0.2$ & $0.8 \pm 0.40$ & $0.4 \pm 0.20$ \\
& Treated & $0.2 \pm 0.0$ & $3.6 \pm 0.60$ & $1.6 \pm 0.70$ & $1.6 \pm 0.70$ & $1.2 \pm 0.50$ \\
\hline
\end{tabular}

Values are mean \pm SEM 
and Nagarajan, 1994; Das and John, 1999; Cakir and Sarikaya, 2005). In reference to these studies and the results obtained from present work, it could be concluded that both propoxur and methyl parathion are significantly genotoxic for the genome of a mosquito even at sublethal dose concentration of $\mathrm{LC}_{20}$. With this it may also be added that polytene chromosomes are also ideal tools for genotoxicity evaluation of harmful environmental chemical mutagens as their giant size presents a mutational change in a magnified profile of various structural aberrations.

\section{ACKNOWLEDGEMENTS}

The authors are thankful to Chairperson, Department of Zoology, Panjab University, Chandigarh for providing the necessary facilities to carry out the present research work under the Center of Advance Studies (CAS) Programme of the University Grants Commission, New Delhi, India Ref: F-5-4/2006(SAP-II), dated 7/12/2006, CAS Phase- I.

\section{REFERENCES}

Agrawal, R.C. (1999). Induction of chromosomal aberrations by propoxur in mouse bone marrow cells. Biomed. Env. Sci., 12(4): 292-295.

Bansal, M. and Chaudhry, A. (2011). Evaluation of mutagenic potential of acetamiprid by dominant lethal test on Culex quinquefasciatus. J . Appl. \& Nat. Sci., 3(2): 171-175.

Barr, H.J. and Ellison, J.R. (1972). Ectopic pairing of chromosome regions containing chemically similar DNA. Chromosoma, 39: 53-61.

Cakir, S. and Sarikaya, R. (2005). Genotoxicity testing of some organophosphate insecticides in the Drosophila wing spot test. Food Chem. Toxicol., 43(3): 443-450.

Chaudhry, A. and Anand, P.K. (2004). Assessment of dominant lethal effects of chlorpyrifos (CPF) using mosquito genetics. Poll. Res., 23(4): 767-771.

Chaudhry, A. and Anand, P.K. (2005). Evaluation of the mutagenic potential of chlorpyrifos (CPF) using polytene chromosomes of Anopheles mosquito. J . Environ. Biol., 26(1): 145-150.

Chaudhry, A. and Barna, B. (2006). Assessment of genotoxic effects of imidacloprid using mosquito genome (Culicidae: Diptera). The Nucleus, 50(1): 51-57.

Chaudhry, A. and Bhinder, P. (2009). Cypermethrin induced mutations in rDNA internal transcribed spacer 1 and 2 of Culex quinquefasciatus (Diptera: Culicidae). J . Appl. Biosci., 35(1): 7-12.

Chaudhry, S., Neetu, Gupta, S. and Chhilar, J.S. (2005). Salivary polytene chromosome mapping of Anopheles (C ellia) subpictus Grassi (Culicidae: Diptera). G enome, 48(2): 241-246.

Clements, A.N. (1996). The biology of mosquitoes. London: Chapman and Hall.

Das, P. and John, G. (1999). Induction of sister chromatid exchanges and chromosome aberrations in vivo in E troplus suratensis (Bloch) following exposure to organophosphorous pesticides. Toxicol. Lett., 104(1-2):
111-116.

De Cassia, S.R., Becak, W., Gaeta, R. and Rabello-Gay, M.N. (1982). Cytogenetic study of workers exposed to methyl-parathion. M utat. Res., 103(1): 71-76.

Evans, H.J. (1977). Molecular mechanism in the induction of chromosome aberrations. In: D. Scott, B.A. Bridges and F.H. Sobels (Eds.). Progress in genetic toxicology (pp 57-74), Amsterdam: Elsevier/North Holland Biomedical Press.

Finney, D.J. (1971). Probit analysis. Cambridge : Cambridge University Press.

French, W.L., Baker, R.H. and Kitzmiller, J.B. (1962). Preparation of mosquito chromosomes. M 0sq. News., 22: 377-383.

Garcia, V.E. and Sanchez, R.F. (1988). Chromosomal polymorphisms and extra bristles of Drosophila melanogaster. Joint variation under selection in isofemale lines. G enetics, 78(2): 91-96.

Grover, I.S. and Malhi, P.K. (1985). Genotoxic effects of some organophosphorus pesticides I. induction of micronuclei in bone marrow cells in rat. Mutat. Res., 155(3): 131-134.

Jain, A.K. and Sarbhoy, R.K. (1988). Cytogenetical studies on the effect of some chlorinated pesticides III. Concluding remarks. Cytologia, 53: 427-436.

Kumar, S.K.B., Ankathil, R. and Devi, K.S. (1993). Chromosomal aberrations induced by methyl parathion in human peripheral lymphocytes of alcoholics and smokers. Hum. Exp. Toxicol., 12(4): 285-288.

Lin, C.M., Wei, L.Y. and Wang, T.C. (2007). The delayed genotoxic effect of $\mathrm{N}$-nitroso $\mathrm{N}$-propoxur insecticide in mammalian cells. Food C hem. Toxicol., 45(6): 928-34.

Mathew, G., Rahiman, W.A. and Vijayalaxmi, K.K. (1990). In vivo genotoxic effect in mice of Metacid 50, an organophosphorous insecticide. M utagenesis, 5: 147-149.

Rabbani, M.G. and Kitzmiller, J.B. (1974). X-ray induced inversions in Anopheles al bimanus. M 0sq. News., 34: 472474.

Rubinstenin, L. and Clever, U. (1972). Chromosome activity and cell function in polytene cells. Development change in RNA synthesis and turn over. D evelop. Biol., 27: 519537.

Rupa, D.S., Reddy, P.P. and Reddi, O.S. (1989). Frequencies of chromosomal aberrations in smokers exposed to pesticides in cotton fields. M utat. Res., 222(1): 37-41.

Rupa, D.S., Reddy, P.P. and Reddi, O.S. (1990). Cytogeneticity of quinalphos and methyl parathion in human peripheral lymphocytes. H um. Exp. Toxicol., 9(6): 385-387.

Rupa, D.S., Reddy, P.P., Sreemannarayana, K. and Reddi, O.S. (1991). Frequency of sister chromatid exchange in peripheral lymphocytes of male pesticide applicators. Environ. Mol. Mutagen., 18(2): 136-138.

Sharma, G.P., Chaudhry, A. and Ahluwalia, K.K. (1989a). Mutagenic activity of two nickel compounds. Cytol. Genet., 6: 555-565.

Sharma, G.P., Chaudhry, A., Sobti, R.C., Dhar, M. and Ahluwalia, K.K. (1990). Effect of mitomycin-C on the genetics of Culex fatigans (Diptera: Culicidae). La Kromosomo II, 58: 1949-1954. 
Sharma, G.P., Sobti, R.C., Chaudhry, A. and Ahluwalia, K.K. (1988). Genotoxicity of two heavy metal compounds lead acetate and mercuric chloride in Anopheles stephensi Liston (Diptera: Culicidae). Cytologia, 53: 263-267.

Sharma, G.P., Sobti, R.C., Chaudhry, A. and Ahluwalia, K.K. (1989b). Chromosomal aberrations and dominant lethals in Culex fatigans due to mercuric chloride. C ytobios., 59: 131-135.

Sharma, G.P., Sobti, R.C., Chaudhry, A., Kaur, R., Ahluwalia, K.K. and Dhar, M. (1985). Effect of some environmental mutagens on the genome of selected invertebrate and vertebrate models including man. Environmental Mutagenesis N ewsletter, 26-28.

Singh, K.R.P. and Patterson, R.S. La-Brecque, G.C. and Razdan, R.K. (1975). Mass rearing of Culex pipiens fatigans Weid. J. Com. Dis., 7: 31-53.

Siroki, O., Undeger, U., Institoris, L., Nehez, M., Basaran, N., Nagymajtenyi, L. and Desi, I. (2001). A study on genoand immunotoxicological effects of subcute propoxur and pirimicarb exposure in rats. Ectoxicol. Environ. Saf., 50 (1): 76-81.

Vijayaraghavan, M. and Nagarajan, B. (1994). Mutagenic potential of acute exposure to organophosphorous and organochlorine compounds. M utat. Res., 321(1-2): 103111.

Zaman, K.M., Gill, R.S., Ahmad, S. and Pardini, R.S. (1994). An insect model for assessing mercury toxicity: Effects of mercury on antioxidant enzyme activities of the house fly, M usca domestica and cabbage looper moth Trichoplusiani. Arch. Environ. Contam. Toxicol., 26: 114-118. 